\title{
Teologías del Sur. El giro descolonizador
}

FICHA BIBLIOGRÁFICA

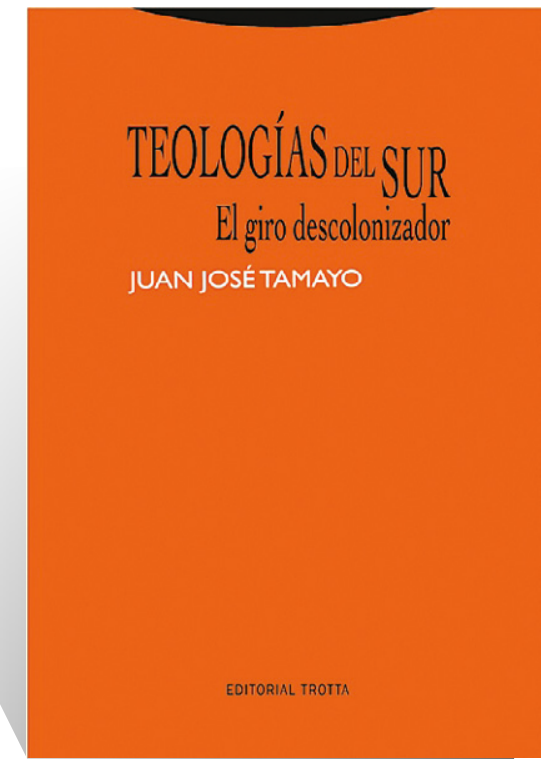

Juan José Tamayo, Teologías del Sur. El giro descolonizador, Madrid, Editorial Trotta, 2017, 256 págs. ISBN 978-84-9879-707-7.

\section{Mirella Romero Recio Universidad Carlos III de Madrid}

El libro de Juan José Tamayo Teologías del Sur. El giro descolonizador centra su atención - como otras de sus ya clásicas obras, pues se trata de uno de los mayores expertos en la materia-, en la Teología de la liberación, como un nuevo modo de hacer teología nacido en la periferia.

La Teología de la liberación nació en América latina pero se extendió con rapidez por el Sur incluyendo movimientos alejados de la teología tradicional, como el feminismo, y en un proceso que el autor ha denominad o el giro descolonizador. En realidad, Juan José Tamayo aborda el estudio de unas teologías nacidas de la disidencia, de la pobreza y la marginación, 
de la inadecuación a un esquema rígido e inadaptado de la teología tradicional en un mundo en continuo proceso de cambio.

El autor realiza una crítica a las religiones hegemónicas guiando al lector a través de diversos apartados que le llevan a tratar desde el paradigma católico-romano medieval, el cristianismo colonial en América Latina, África y Asia, a la modernización y colonización del mundo musulmán o la tipología hegemónica de las religiones. Una vez realizada esta introducción en el primer capítulo, el autor plantea el desarrollo de las teologías emergentes y de las teologías poscoloniales para, a continuación dedicar cinco exhaustivos capítulos a abundar en el estudio de las Teologías africanas, la Teología negra estadounidense, las Teologías asiáticas, las Teologías latinoamericanas y el Sumak Kawsay, y la teología indígena. En el capítulo 3, dedicado a las Teologías africanas, acerca al lector, a través de seis apartados, a la culturalista, de la liberación, de la reconstrucción, contextual surafricana y Ubuntu. En el capítulo dedicado a las asiáticas fija su atención en la minjung coreana, dalit en India, la lucha en Filipinas, hindú, budista, musulmana, palestina y judía, mientras que en el centrado en las latinoamericanas incide en las indígenas, afrodescendientes, ecológica, poscolonial, religiosa y cultural, queer y teo-poética de la liberación. No se olvida, como ya se ha señalado, de la teología negra estadounidense, ni del Sumak Kawsay, que está en la base de la teología indígena de la liberación y que se desarrolló en el contexto de las dictaduras militares en América latina. Todas ellas son tratadas con rigor y ubicadas en sus contextos geoculturales, económicos y políticos.

Todas las teologías emergentes tratadas por el profesor Juan José Tamayo en Teologías del Sur. El giro descolonizador, han generado discursos alternativos a las teologías eurocéntricas de carácter colonial y han intentado, e intentan, responder a los desafíos de nuestro tiempo, especialmente, la desigualdad, los fundamentalismos, el patriarcado, el militarismo o la pobreza. Se trata de teologías que abogan por el diálogo y los discursos alternativos en un mundo que parece, en muchos momentos, abocado a la intransigencia religiosa y política. Tamayo plantea a través de una obra novedosa y exhaustivamente documentada la necesidad de tener presentes estas teologías que cuestionan los sistemas de dominación y abogan por el diálogo interreligioso e intercultural, interétnico e interdisciplinar.

La obra de Juan José Tamayo es, en resumen, una obra importante desde el punto de vista teológico pero también histórico, pues es fruto de una intensa investigación que aborda y describe nuevos planteamientos teológicos ahondando en las raíces de los mismos. 